\title{
Critical Self-Reflection as Moral Practice: A Collaborative Meditation on Peer Review in Ethics Consultation
}

\author{
Andrea Frolic and Susan B. Rubin
}

\section{Introduction}

With "The Zadeh Scenario," Finder offers us a gift...a rich and thoughtful firstperson account of the gradual unfolding of a specific ethics consultation conducted by a specific ethics consultant in a specific context. This is not your average case report, stripped to the bare facts and devoid of the ambiguity of real-time human interactions. It's also not simply an example of thick description, offering the reader a detailed account of the context out of which an abstract ethical dilemma has emerged, with the ethics consultant describing all from a distance, above the fray. What Finder offers and models for us instead is something entirely new and different. He offers us a case narrative into which he has chosen to place himself squarely and explicitly. And in the spirit of "peer review" he has generously revealed his own inner dialogue in response to twists and turns in the case, sharing his personal reflections as events unfolded, and his musings about various actions he took and choices he made in his role. By inviting us to ponder his story about the story of the case, he generously extends a gift to us: the opportunity to reflect on his-and therefore our own-consultation practice, and the opportunity to try a new kind of peer review.

One of the first things we were reminded of in reading Finder's narrative account of his practice is how, in any setting, individuals inevitably become "characters" based on how other people perceive them and the social roles that they play. This is no less true in ethics consultation, and proved to be an important entry point for us into the peer review process, particularly with respect to how the involved parties

\footnotetext{
A. Frolic $(\bowtie)$

Office of Clinical \& Organizational Ethics, Hamilton Health Sciences, McMaster University,

Hamilton, ON, Canada

e-mail: frolic@HHSC.CA
}

S. B. Rubin

The Ethics Practice, Oakland, CA, USA 
and Finder himself viewed his role and contribution. In "The Zadeh Scenario"-an account of a clinical case involving two ethics consultants, Finder and his colleague, Steve Moore-Dr. Broukhim plays the role of the "physician of last resort," a doctor beloved by his patients for enabling them to continue their fight against cancer when others insist on surrender. The family members who attend to the patient in this narrative through her long hospitalization (Mrs. Hamadani's son and two daughters) acquire the reputation of being not only lovely and devoted, but also difficult, intrusive, and bullying to staff. And as a visible part of organizational life, the ethics consultants too become "characters" in the social world of the hospital.

Through the narrative we see how both family members and clinicians assign motivations and attributes to ethics consultants that may have no grounding in (and, in fact, may be counter to) our own self-perceptions, roles and responsibilities, or lived practices. And this should be both a reminder and an invitation to us as individuals and as a field. As ethics consultants we tend to be more comfortable exploring other characters than turning the gaze back on ourselves. But critical self-reflection is necessary for both solid practice and meaningful peer review. In this chapter we argue that as ethics consultants, both individually and collectively, we must have a clear sense of our professional identity and a rationale for our practices (Rubin and Zoloth-Dorfman 1997). We have to take responsibility for independently establishing what our role is and is not, for defining what we will and will not do, and for setting and managing the expectations others have of us. Together as a field we have an obligation to ask and debate the sometimes challenging questions raised by others' perceptions and expectations of us. For example, is it our job to have the tough conversations with families, or to convince them to go along with the recommendations of the medical staff? Is it our job to contribute to reducing length of stay or to enhance patient satisfaction? Given the manifold pressures facing hospitals, it is not surprising that others will be happy to assign us roles that may align with the organizational priorities of the day. But it is incumbent upon us to be prepared to tell our own story, to articulate our own roles, to engage in continuous education about who we are and what we do, to correct potential misperceptions and to hold ourselves accountable. Sometimes we will disappoint or even anger others in the process. Nevertheless, we argue that we can and we must rise to the occasion.

But in our current situation, lacking the clearly recognizable trappings of a formal profession (like practice standards and credentialing processes) how do we even begin to articulate and defend our roles and responsibilities? How do we evaluate the quality and effectiveness of our unique roles as ethics consultants? How do we avoid simply being "good employees" or "trusted team members" by following the orders and priorities of our employers and clinical coworkers? How do we take independent moral responsibility for our practices when they are largely self-defined and self-monitored, and frequently invisible to even our closest colleagues?

Finder has afforded us the opportunity to experiment with peer review of a detailed case narrative as one method to enable rigorous reflection on these questions. By writing a detailed account of one of his ethics consultations-including his subjective experience of the consult, the clinical facts and social dynamics of the 
situation, and renderings of conversations over a period of days-we get a snapshot of his ethics consultation practice. The existence of this narrative is itself remarkable. As ethics consultants we spend a lot of time scrutinizing other health care providers' practices, but we don't turn that mirror on ourselves as often as we should. So much of our work is opaque to the public, to our employers, even to ourselves. When we tell people about what we do for a living we let the phrase "ethics consultation" roll off our tongues, but what does that really mean? What is the nitty-gritty, moment-tomoment manifestation of that work? The very existence of Finder's narrative points to a gap in our empirical knowledge of the field vis-à-vis what we are actually doing when we are doing ethics consultation (Frolic 2011). This narrative invites substantive and critical examination of "the ethics consultant at work in his native environment," affording the reader a rare glimpse into one person's lived practice.

This is a very different kind of peer review process from those involving evaluation of consult records or professional dossiers or even oral examinations using theoretical cases. It provides a clearer picture of actual practice (rather than merely demonstrating analytical prowess); however, it entails a great deal more exposure and vulnerability. We believe Finder's reflective piece offers an example of a practice that can and should shape the future of ethics consultation, especially now as we move towards professionalization and certification. We offer a deep bow of gratitude to Finder for his courage in making his practice... at least in this case...transparent to others. It affords us as a community of practitioners and scholars a rare opportunity to contemplate the challenges of mapping, molding and measuring the practice of ethics consultation. His moral commitment to transparency and selfexamination is exemplary.

This chapter represents the composite reflections of both its authors. We use minimal references, drawing instead on our own practical wisdom acquired over the course of our careers, as peer reviewers tend to do. And we write in the first person plural rather than the third person; this retains the conversational and contemplative style of Finder's scenario, and compels us to own and personalize our observations about Finder's practice. In this way we share in the spirit of vulnerability he so eloquently and generously models in his narrative.

Our reflections are organized into two sections. First, we describe what we perceive to be the appropriate nature, role, scope and practice of an ethics consultant. Against this frame, second, we offer a close reading of "The Zadeh Scenario," focusing on Finder's portrayal of his role as an ethics consultant and the normative and procedural dimensions of his practice.

\section{The Nature and Role of the Ethics Consultant: A Humble Declaration of Independence}

If an ethics consultant were an animal...which animal would it be? The answer to this question - be it a platypus, a watch dog or a house cat-says something about how the respondent imagines the role of ethics consultation in contemporary 
healthcare. Similarly, the process of "peer review" is premised on the notion that ethics consultants not only have a clear role, but also standards against which a colleague's performance can and should be measured as good or bad. At this point in history, these standards are largely imagined, individual and idiosyncratic. Despite years of debate about this in the American Society of Bioethics and Humanities (ASBH) and by Canada's Practicing Healthcare Ethicists Exploring Professionalization (PHEEP), and despite the promulgation of documents like the Core Competencies (ASBH 2011) and the Model Role Description for Ethicists (Chidwick et al. 2010), in our view we still don't really have agreement on a number of basic issues that form the conceptual foundation of any real practice standard. Issues such as:

- What are we doing when we say we're doing ethics consultation? Facilitation? Decision Making? Mediation? Offering a kind, compassionate, supportive presence? Offering the perspective of the outsider-what Larry Churchill (Churchill 1978) named "the role of the stranger" years ago? Being an integral contributing member of the health care team, even "going native" in order to effect change?

- What goals do we have in mind? Ensuring the best care for the patient? Defusing conflict? Reducing length of stay? Reducing "non-beneficial treatment?" Drawing attention to the ethical dimensions of clinical decisions and helping to facilitate a thoughtful process of decision making grounded in careful and deliberate ethical analysis?

- How do we know if we are successful in meeting these goals? Should our evaluative measures focus on the experiences of stakeholders, including patient or staff satisfaction? Or should we favor more procedural measures, like whether the conflict was resolved or legal action was averted? Or should we concentrate more on longitudinal effects, like enhanced awareness of the moral dimensions of care and reduced moral distress?

In fact, without much empirical evidence to the contrary, we are guessing that the answers to these questions are likely to be widely divergent because we all enact our roles differently, with different goals in mind and with different degrees of success. That's precisely what makes any kind of standardization and meaningful peer review particularly challenging: by what standard are we measuring our peer's practices? Perhaps the first and most valuable step is to name our own biases about what we think are the hallmark features of ethics consultation, and to offer some account and defense of them. So we begin by articulating our answers to some of these questions, to declare where we stand, as a necessary preface to a critical peer commentary on Finder's narrative.

For us, the core commitments of the role of the ethics consultant that should guide his or her practice are:

1. Role clarity: The ethics consultant is not the moralist - and therefore shouldn't present herself as the knower or arbiter of all things good and right. Rather, it's the ethics consultant's job and unique contribution to support a deliberative process that includes: helping to identify the ethical dimensions of whatever 
decisions or issues are giving rise to questions/concerns; identifying any underlying value conflict or value uncertainty; exploring and giving voice to the various perspectives of the different stakeholders/involved parties about the value conflict/uncertainty; facilitating meaningful discussion about the ethical questions at stake among them; and finally, offering guidance, recommendations or advice based on the information gathered and a consideration and analysis of the ethical appeals/issues at stake. It is crucial for us to be able to articulate how the role/scope of the ethics consultant overlaps with and is distinctive from other health professionals, including chaplaincy, social work, palliative care, risk management, etc. Ethics consultants must be prepared to articulate their distinctive role to stakeholders throughout the consultation process, and to defend the boundaries of this role when others attempt (intentionally or unintentionally) to shift or cross these boundaries (for example, by recruiting us as advocates for their perspective).

2. Normative analysis: While it's not the job of the ethics consultant to be prescriptive or determinative, in our view there is an inescapably normative dimension to the work. Our focus is on the "ought" questions. We're not there to simply name and comment on what is. Or to be passive observers. Or even to offer a supportive presence. We ought to have something unique and value added to contribute. And that contribution shouldn't be based simply on our ability to play well with others or make people feel safe, comfortable, and supported. It should be grounded in the discipline of ethics and should contribute something recognizably different and valuable to the equation. For example, while many health professionals might be able to describe a conflict about a treatment plan ("to resuscitate or not to resuscitate...that is the question"), the ethics consultant should be able to articulate the moral dimensions of the conflict and bring ethical theories (like consequentialism, deontology, or virtue ethics) and/or different methodologies (like principlism, casuistry, or narrative ethics) to bear on the situation. This is one of the unique contributions of ethics consultation to the social world of healthcare.

3. Procedural clarity: The ethics consultant ought to bring form, structure, and discipline to what otherwise might be an idiosyncratic and even freewheeling approach to the difficult questions that give rise to requests for ethics consultation. This form and structure not only ensures the integrity of the consultation process, but it also helps distinguish ethics consultations from all of the many other conversations and interventions that are likely taking place around a difficult case (such as patient/family care conferences or palliative care consults or conversations with the involved social workers or chaplains). By taking responsibility for keeping the focus of ethics consultation on the ethical issues at stake, and for bringing the tools, frameworks, and resources of the field of ethics to bear on the particular case, the ethics consultant helps ensure consistency and quality across ethics consultations. Though the methods of implementation employed to achieve those ends might vary, all ethics consultants ought to have ways to make their services known and clear mechanisms through which they can be accessed. And once accessed, we contend that ethics consultants must 
take responsibility for defining the nature, structure, scope, and even pace of the ethics intervention. There should also be certain key recognizable components for which the ethics consultant should take responsibility such as: (1) Investigating and identifying what $i s$ the case? (What is the ethical dilemma? What is known factually? What values are at stake? Who is involved and what are their perspectives on the ethical dilemma?); (2) What might be the case? (What options have been or might be considered? What might be possible?); and (3) What ought be the case? (This involves exploring the normative dimensions of the case: What is the good/right/best thing to do in this case? Which possible next steps might be ethically defensible and which might not be? How do the options connect with the values of the various stakeholders? What is the consultant's recommendation?) Procedural transparency is an essential part of ethics consultation to engender trust and integrity. Thus, it is important for involved parties to understand that ethics consultations have beginnings and ends, and to know where they are in the process, and what the ethics consultant is doing and why along the way.

4. Critical self-reflection: Another hallmark of ethics consultation should be the creation of space for self-reflection about our own practices and about where we stand in the stories in which we get engaged. This is arguably an important practice for all health professionals. However, given that the "technical" dimensions of ethics consultation involve moral deliberation, conflict mediation and making space for epistemological pluralism, critical reflection on the question, "Where do I stand in this?" is particularly crucial: What life experiences, commitments, allegiances, insider knowledge, and prior cases might be shaping my analysis of the case? How do my own histories and biases influence how I approach stakeholders, how I comport myself, what I say and when? An ethics consultant, even one who is an outsider to the organization, cannot articulate the "view from nowhere" and all of us (being human) have particular moral blind spots. Humbly, we must acknowledge the influences on our behaviors and thoughts, and in some cases, we might even need to disclose these influences to others to ensure the integrity of the process.

Another form of self-reflection essential to ethics consultation involves the critical appraisal of our performance: How well did I follow the procedures/norms that are supposed to govern my practice? How effective was I in staying true to my role and scope? What was the quality of my normative analysis? Ideally, we should have access to multiple sources of data to appraise the quality of our work (client satisfaction surveys, anecdotal feedback, peer support, etc.), but we must also have the discipline to pause in the midst of our hectic days to contemplate: "Was I true to my role... did I do my best... and did it make a difference?"

The above summary of the hallmark features of the role of the ethics consultant represents a much-abbreviated version of the idiosyncratic standards that govern the authors' ethics consultation practices (though it must be acknowledged that we may each enact our roles in distinctive ways). Despite coming from different disciplines, practicing in different organizational contexts and in different countries, we readily 
agreed on these core features and used them to inform our analysis of Finder's narrative. We found ourselves remarkably in sync in terms of what surprised or gratified us in reading Finder's account of his role. What follows is a synthesis of our perspectives in the form of our peer review of Finder's case narrative, organized around the four core commitments articulated above.

\section{A Peer Review in Four Parts}

\section{Role Clarity}

There are numerous explicit and implicit references to the role and scope of practice of the ethics consultant in "The Zadeh Scenario." The consultant is asked to:

- follow the patient closely to try to provide support to the family

- provide more care for the family in these trying times

- delineate the ethical issues

- explain the clinical information

- get the family to make a decision or checking back with them re: their decision

- help the physicians have meetings with families

- defuse situations

- make suggestions (e.g. the ethics consultant was the one to recommend the n-g tube as a way to defuse one situation)

- translate between the physician and family

- make clinical referrals (e.g. the ethics consultant is the one who contacted the oncologist years prior)

And there are references to what the ethics consultant is not being asked to do, specifically to persuade or to be abrasive to the patient's family.

What was particularly striking to us about the narrative is how much Finder's involvement and role seems to be one of providing emotional and personal support to the family. We question whether that's the legitimate role of the ethics consultant. Yes, we should listen respectfully. Yes, we should acknowledge emotion. Yes, our presence is often supportive. However, if this is all we do, are we really doing what is more properly the work and legitimate role of other professionals such as chaplains and social workers, who are better equipped and trained to provide that specific kind of support? We think it's worth asking what happens to the distinctive contribution of ethics if the role is defined primarily as one of providing support.

It was interesting too that there's an explicit reference to the ethics consultant's role not being to persuade the family. Unfortunately, Moore (Finder's fellow ethics consultant) frequently found himself getting pulled into conversations between doctors and family members that seemed fundamentally about trying to persuade them. Given this context, and the fact that the family does not appear to have been explicitly told about the distinctive role of the ethics consultant, their perception that 
Moore is there to advocate for the physician's perspective is understandable. And this is not an uncommon scenario. Ethics consultants are frequently enlisted when the team wants some added ammunition, if you will, and it is precisely at these moments that we think the ethics consultant needs to stand firm and in a place of integrity about what her legitimate roles and scope of practice are-to guard against being used to further others' agendas, however worthy or persuasive.

We think it is important to appreciate the fact that individuals in conflict naturally want to gather allies to their cause; without clear boundaries and the capacity to articulate them, it is easy for consultants to get "recruited" to one side or another. Or "scope creep" can occur, where difficult or unpleasant tasks are downloaded to the ethics consultant, such as the job of breaking bad news, or calming an angry family member, or saying "no" to someone who desperately wants a "yes."

This brings us back to the issue of expectations. The narrative excerpts the oncologist's note in which the desired contribution of the ethics consultant is described. In addition to hoping the ethics consultant will be able to provide support to the family, he also hopes the ethics consultant will be able to delineate the ethical issues involved in the care of this terminally ill patient. We agree that a focus on the ethical dimensions is intrinsic to the ethics consultant's role, but unfortunately we found that missing in the narrative. To put an even finer point on it, we want to argue that delineating ethical issues - while perhaps a necessary part of the ethics consultant's role/contribution-is also not sufficient on its own. The ethics consultant ought to be responsible for not only identifying but also actively engaging in discussion of the ethical issues, offering an analysis, and, where appropriate, making some recommendations.

Throughout the narrative we found instances of potential role confusion, either in terms of how the ethics consultants were conceiving their contribution or how others perceived them. This underscores for us the importance of being crystal clear about our unique role and contribution. We must be prepared to educate patients, families, and our colleagues about our role, and we must be constantly prepared to defend the boundaries of our role. In this way we can maintain a sense of integrity and protect against inappropriate uses of ethics consultation.

Not only can lack of clarity regarding the ethics consultant's role create confusion or unrealistic expectations, it can also create misunderstandings. For example, in Finder's narrative the family is described as feeling harassed by Moore's persistence in coming to check back with them. Clearly that wasn't his intention. But what in fact was he trying to do? What did he think he was doing anyways by "checking back" with them? And did he make that clear to the family? It seems like his intention was to see whether the family had had a chance to think more about the question he'd posed to them in a care conference, specifically, why was it that they were willing to proceed with aggressive interventions despite the various doctors' concerns? The question is a good one because it speaks to the family's motivation, goal, underlying intention, rationale and justification. These are all good to explore, but our suspicion is that it skewed the family's perception of Moore's role especially if it gave them the impression that they were to answer to him. This is a great example of how in the absence of early and explicit communication about the role 
and scope of the ethics consultant, confusion may ensue and various parties may actively try to recruit the ethics consultant to their "side" and then feel frustration when the ethics consultant doesn't perform according to their expectations. When the family first approached Finder, he could have taken that opportunity to tell them a little bit about the role of the ethics consultant in general; this may have helped to diffuse their frustration with his colleague Moore.

Although we may have a knack, as Finder clearly does in this narrative, for making connections or making people feel safe and comfortable and cared for, and although we may be recognized by our colleagues and patients/families for this capacity, it is important to ensure that our practices are reflective of and grounded in our actual role as ethics consultants.

\title{
Normative Analysis
}

An essential first step for an ethics consultant is to notice how those involved are describing the problems/challenges they are facing, and to invite and guide them to see their concerns through the broader lens of ethics. It's curious to us that in the narrative neither Moore nor Finder seems to take that next critical step. We are given a clear account of one physician's concerns but no separate account of the attendant ethical issues they raise. We quote the physician here:

\begin{abstract}
In addition to myself, Dr. Smith, ICU attending, Dr. Nadouri, nephrology consultant, nursing staff, and case management have all spoken with the family and discussed the fact that the patient's overall status is poor. Nonetheless, the family continues to request the patient be maintained as a full code and that dialysis be considered. We will continue to talk with the family and try to help them understand that these measures are not going to be helpful and most likely might be harmful, including shortening her life. The family fully understands these issues. All their questions have been answered. They remain at bedside and have told me that if the patient codes, at that point they will let the medical staff know if the patient should be intubated or not. Patient will remain at this point full code. I spent 8:00 am-11:30 am this morning in the ICU providing care for Mrs. Hamadani (Finder 2018: 31).
\end{abstract}

The team appears to believe that bludgeoning the family repeatedly with more clinical information and opinions will cause them to capitulate to their recommendations, something one would hope an ethics consultant would have noticed and drawn attention to. But despite 3.5 hours of conversation, and over 20 pages of narrative, many substantive questions remain unanswered that might have enhanced the quality of the moral deliberation around this case, and may have enabled the various "camps" in the case to gain insight into one another's perspectives and values:

- What is the family's goal for their mother's treatment? Can this goal be achieved? What is really driving their decision-making?

- What are the consequences to the patient/family/team of not having a clear plan for when her heart stops? How might this scenario play out? 
- Who is the appropriate surrogate decision-maker? Who is the legal surrogate decision-maker?

- What are the obligations of the parties involved? Does local law articulate how families are supposed to make decisions for incapable patients? Are physicians obligated to get consent to withhold a treatment like CPR or can they write unilateral DNR orders?

- Does staff believe that the patient is being harmed by the family's decisionmaking? What is the nature of this harm?

- How do different health professionals perceive the case differently? How can they be supported to articulate and address their moral distress and to work together as a team?

- Mention is made of a hospital policy about medically inappropriate treatment. Why is this not applied in this case?

- And most importantly, where is the patient in all of this? What is her day-to-day experience like now? Who is she? What are her desires, goals and wishes? What did she say about her care when she was capable? How did she feel about the aggressive cancer treatment she received? Did she ever talk about dying? Did she recognize that her cancer was terminal? What gives her pleasure? What makes her life meaningful? How would she define quality of life?

When he sees the family again Finder states: "I did not inquire about whether they had thought more about CPR and DNAR or if there had been discussions of stopping the dialysis. Rather, I kept my focus on how they were holding up, especially the sisters who also had families for which they had responsibilities. I also asked about their father and the now unfolding plans as he was about to be discharged" (Finder 2018: 36). It is not clear why he steers away from engaging in analysis of the issues and focuses instead on emotional support. It is worrying that fear of upsetting the family or physician or anyone else would lead to the avoidance of precisely the questions and conversations that are most essential for the ethics consultant to engage, however painful, to ensure ethical patient care. The narrative does not offer any explanation for why Finder made the choices he did and what he thinks his role should have been in this case. It leaves us further wondering whether Finder would hold his behavior out as exemplary or, in retrospect, how he would adjust his practice.

Most disturbingly, the patient-as-person remains largely off-stage throughout the entirety of "The Zadeh Scenario," something one would expect the ethics consultant to be aware of and responsive to. Her inert body is a battle ground between the so-called loving family members (though we question whether it is really love or grief that is motivating their decisions) and the righteous, but impotent team that pushes decision-making onto the family and then resents them for the decisions they make. Her absence from the story provides a stark reminder of how quickly conflict can feed a downward cycle in relationships that can become self-reinforcing as patterns of communication are formed and what is most central to the conversationthe patient-is lost. 
We believe that the essential roles of the ethics consultant are to identify the ethical dimensions of a case, to educate parties about relevant ethical standards, and to analyze the ethical dimensions of a case in light of the facts and relevant standards. In our minds, Finder seems to miss an opportunity to engage in the substantive work of ethics consultation. He offers support and empathy, but the crux of the conflict is neither named nor unpacked: that is, what treatment options are in the patient's best interests and in accord with her previously expressed wishes?

Let us clarify that we don't necessarily think that the outcome of this case is "wrong." We think Finder artfully portrays the merits of both sides of this conflict. We can't presume from this story that one side is correct and the other is incorrect, and this quality of the narrative alone is admirable. For in the genre of case reports, ethics consultants frequently vilify one side and valorize the other. However, we remain frustrated that we don't have sufficient information to judge the ethicality of the outcome of the case, because key questions seem never to have been addressed. It is this lost opportunity to engage in substantive analysis that is the source of our greatest frustration and concern in reviewing "The Zadeh Scenario."

\section{Procedural Clarity}

Having procedural clarity about the various phases of ethics consultation can help ensure appropriate attention to the normative dimensions of the consultative process, keep the ethics consultant on track and set clear expectations for interactions between the consultant and the various stakeholders. The lack of this kind of procedural clarity was notable in Finder's narrative. At the same time, Finder and Moore seem to share certain process elements in their approach to ethics consults including:

- Talking to stakeholders one-on-one

- Attending family meetings, primarily to listen and ask questions and offer suggestions

- Reading the patient's medical record

- Documenting in the patient record

And there seem to be some admirable features of Finder's practice including the following:

Mindful, Non-Judgmental Respectful Listening A commitment to this quality of listening seems to be an integral part of Finder's practice. The narrative is full or references to Finder listening and listening well. We agree that making it a practice to listen deliberately and thoughtfully is certainly an important building block in establishing trust and rapport which may be necessary in order to successfully delve into the harder material. However, we would argue that listening is a necessary but ultimately insufficient skill/contribution of the ethics consultant. Finder's narrative left us concerned that he might have risked creating the misimpression that the eth- 
ics consultant's role is simply to listen as opposed to being an actively engaged participant contributing something unique to the process/case. That being said, we are painfully aware of how easy it is to make a misstep by prematurely jumping in with pronouncements/opinions based on incomplete information in the interest of demonstrating one's value in a difficult situation. It's also possible to make the mistake of accepting the mantel of the "moralist" who has some direct access to the truth and whose job it is to enlighten everyone else. And so we commend Finder for making neither of these mistakes.

Continuity of Care Another feature of Finder's practice seems to be "following cases." This is something that was striking for us and raises real questions about the role and scope of practice as well as the kinds of expectations such a practice may foster. Finder makes reference to relying on the electronic medical record to notify him when patients the ethics service has been involved with in the past are readmitted, presumably so ethics can "check in" with them and continue to "follow" the case. While this may provide some benefit in cases involving recurrent ethical conflicts, this is also a marker of how much Finder's ethics practice is embedded/nested in a medical model. We worry this could lead to some inadvertent role confusion (What exactly is the ethics consultant contributing by "checking in" on a previous case?), as well as potential violation of the patient's privacy.

Visible Integration "The Zadeh Scenario" exemplifies the visible integration of the ethics consultant into the clinical context of patient care. Finder is obviously not spending all of his time in an office far removed from patients, which we both applaud. He doesn't expect people to come to him, he goes to them. This allows him to see and understand the context of care, to observe interactions between parties in a "natural" environment, and to be more meaningfully accessible. This is particularly evident in Finder's attention to geographical space and the context of conversations. Such integration into the flow of clinical care can enable: relationships of trust with clinicians; personification of issues that otherwise can be very abstract; better fact gathering and direct communication with stakeholders. But it also potentially raises the host of concerns addressed in the literature about "going native," including losing critical distance/perspective and cementing alliances that might disadvantage certain stakeholders in a case.

But as noteworthy and positive as each of these elements of Finder's described practices are, we think there are downsides to them as well. What strikes us most about the methods described are their informality and their seeming disconnection from what we see as the essential and unique contribution of the ethics consultant -the focus on the normative questions raised by the case. The ethics consultant is portrayed as one who wanders in and out of units and meetings, whose primary role apparently is to "check on things" and to "see what is happening" and "offer support." But what does all of this checking and seeing really contribute? Finder himself expresses concern over the lack of clarity in his role during his last family meeting: "Given the set up, I wasn't sure if I was there to help Dr. Broukhim or to facilitate a conversation, or both, or just to bear witness, so to speak. Accordingly, I 
waited to see what came next rather than assume that I was to begin this conversation" (Finder 2018: 38). We believe this case demonstrates that without a clear consultation process - a discrete beginning, middle and end, and clear markers along the way - the work of normative analysis and moral deliberation and the intended role of the consultant can easily get lost in the drama of the conflict.

This case is a classic example of an ethical conflict. There are two parties who clearly disagree about what the right thing to do is regarding a patient's plan of care. Not all consultations present this way, but such cases seem well-suited to bioethics mediation or a formal committee consultation process. A formal process serves several purposes:

- It allows multiple parties to hear one another simultaneously and to communicate directly with each other. If the ethics consultant only talks to one party at a time, they are in danger of triangulating relationships and compounding the miscommunication that so often happens in fragmented hospital care.

- It allows for asking difficult questions and telling difficult truths to one another in a supportive setting.

- It can ensure that all parties' values and concerns are heard, through facilitation by a neutral person.

- It can focus primarily on a narrow function/goal, that is, naming and examining the ethical dimensions of the case, as opposed to building relationships or information-sharing - the typical functions of family meetings.

These functions cannot be fulfilled without some formalization of both the ethics consultant's role and process. In a few places it is mentioned that the nurses are deeply distressed about the "futile" care being provided to the patient. What is the role of the ethics consultant in addressing this distress? It is impossible to tell from this narrative if and how the voices of the bedside staff were included in the consultation process. For example, in a formal consultation process, the ethics consultant could invite a member of the nursing staff to share her perspectives on the patient's experience of her life, its quality, its challenges, etc. along with the concerns of the bedside caregivers. In addition, the ethics consultant could provide a case debriefing or similar process for nursing staff to articulate their values and concerns (either concurrently or retrospectively) to address their moral distress and to enhance their understanding of the ethical dimensions of the case. This could be a unique contribution of the ethics consultant to alleviate the mounting tensions in the ICU, to build capacity and to address the potential fall-out of this case after the patient has died.

But this narrative points to a second procedural challenge. It does not appear that ethics consultation in this case contributed to any positive outcome, beyond a good relationship between Finder and the family. It did not enhance relationships between stakeholders or support a deeper understanding of their diverse moral perspectives (if anything it appears that the nursing staff was increasingly alienated throughout the process). It did not result in a clearer plan of care for the patient. It did not result in the patient's voice being heard and honored. From an administrative perspective, was the benefit gained worth the cost? It is difficult to imagine how Finder and 
Moore would measure the quality of their consultation process, apart from whether people liked them or valued their support. But what about other quality markers like ethicality, adherence to process measures, or capacity-building? In fact, without a clear beginning, middle and end to the case, it is impossible to define any outcomes at all or to make judgments about the effectiveness or quality of the consultation as a distinctive contributor to a particular case.

\section{Critical Self-Reflection}

"The Zadeh Scenario" has given us an opportunity to reflect on and deepen our understanding of the necessary components of a rigorous and meaningful process of self-reflection. If we are to hold ourselves accountable to continually reflect on and improve our practices, we need to apply rigorous normative analysis to ourselves and to our practice, just as we do for our consultation cases. In other words, it is not enough to be able to describe to ourselves or even to our peers what we did or what we do. Just as we offer a response to the classic question of ethics when we are called to offer ethics consultation in specific cases - what is the right/good act and what makes it so? - so too ought we be able to offer a normative defense of our practice - what was the right/good way to approach this case, what makes that so, and how well did we do in upholding that standard? We need to be able to offer an account and a defense to ourselves and to our peers, not only of what we did, but why we did it and why we thought it was the good or right thing. We need to be able to describe: our thinking and underlying rationale; the beliefs, assumptions, and biases that guided our choices; the tradeoffs or compromises we may have consciously or unconsciously been willing to make; and how we might have allowed ourselves to be impacted by the external constraints under which we have been asked to practice. Finally we need to be able to critically appraise how well we managed the core commitments that we argue should guide the practice of ethics consultation: role clarity, normative analysis, procedural clarity and critical self-reflection.

In reviewing Finder's narrative, we are struck by how he seems to have shied away from that sort of critical normative analysis both about the case itself, and about his own practice. Though he is clearly committed to self-reflection in that he has offered a rare and welcome look into his internal thought processes, and has unabashedly and without reservation invited public peer review of his practice, for some reason he stops short of sharing his own self-appraisal of his practice. He offers description without analysis, and as reviewers, it has left us wanting more. We don't have any sense of whether Finder would endorse or criticize his conduct in the case. We don't get an account or defense of the role he chose to assume, decisions he made about engaging or not engaging the normative questions raised by the case, or procedural choices he made in organizing his involvement in the case. And it makes us wonder why. Is Finder withholding his own commentary so as not to bias or influence the conversation or process of peer review? Is he hesitant to presume 
consensus about the standards to which we should hold ourselves accountable and is therefore at a loss for how to responsibly critique his practice? Do a different set of questions altogether arise for him in evaluating his practice, making the questions we've raised less compelling or relevant for him?

Whatever the reason, the absence of normative self-reflection in the narrative Finder has offered highlights the necessity of incorporating it as a key component of a process of meaningful self-reflection. And to create accountability, that process of reflection can't exist in an insular, self-referential vacuum. That is where we must support one another as colleagues in the field, to create and hold the space for that sort of reflection, to demand it of one another, and to create safe opportunities for peer review so that we can hold our practices up for others to examine and evaluate, as Finder has modeled.

\section{References}

American Society for Bioethics and Humanities (2011) Core competencies for healthcare ethics consultation, 2nd edn. American Society for Bioethics and Humanities, Glenview

Chidwick P, Bell J, Connolly E, Coughlin MD, Frolic AN, Hardingham L, Zlotnik Shaul R (2010) Exploring a model role description for ethicists. HEC Forum 22:31-40

Churchill LR (1978) The ethicist in professional education. Hast Cent Rep 8(6):13-15

Finder SG (2018) The Zadeh Scenario. In: Finder SG, Bliton MJ (eds) Peer review, peer education, and modeling in the practice of clinical ethics consultation: the Zadeh project. Springer, Cham, pp 21-42

Frolic AN (2011) Who are we when we are doing what we are doing?: the case for mindful embodiment in ethics case consultation. Bioethics 25(7):370-382

Rubin S, Zoloth-Dorfman L (1997) Navigators and captains: expertise in clinical ethics consultation. Theor Med 18:421-432

Open Access This chapter is licensed under the terms of the Creative Commons Attribution 4.0 International License (http://creativecommons.org/licenses/by/4.0/), which permits use, sharing, adaptation, distribution and reproduction in any medium or format, as long as you give appropriate credit to the original author(s) and the source, provide a link to the Creative Commons license and indicate if changes were made.

The images or other third party material in this chapter are included in the chapter's Creative Commons license, unless indicated otherwise in a credit line to the material. If material is not included in the chapter's Creative Commons license and your intended use is not permitted by statutory regulation or exceeds the permitted use, you will need to obtain permission directly from the copyright holder. 